\title{
Close Kinship Between Psychology And Orthodontics
}

\author{
RuchaBhatkhande $^{1^{*}}$ AbhijitMisal $^{2}$ NandlalToshniwal ${ }^{3}$ \\ ${ }^{1}$ Post- Graduate Student (Department Of Orthodontics And Dentofacialorthopedics), Rural Dental Sciences, \\ Loni, India \\ ${ }^{2}$ Professor And PG Guide (Department Of Orthodontics And Dentofacialorthopedics), Rural Dental Sciences, \\ Loni, India \\ ${ }^{3}$ Professor And Head (Department Of Orthodontics And Dentofacialorthopedics), Rural Dental Sciences, \\ Loni, India
}

\begin{abstract}
Psychological development is a dynamic process. Psychological development begins at birth and proceeds in an ascending order through a series of sequential stages manifesting into various characteristic behaviour. These stages are governed by genetic, familial, cultural, interpersonal and interpsychicfactors. Since most part of the success of the orthodontic treatment lies in the compliance of the patient, it is imperative for an orthodontist to be aware of the emotional health of the patient. Most part of orthodontic treatment involves correction of the dentofacial abnormalities. Such an individual with inappropriate deformed facial features often shows increased anxiety and difficulty in adjusting with his life and changes occurring around him or her. Sometimes the overt nature of their deformity gives them the characteristics of physical handicap. The aim of this article is to understand the various aspects of child and adult psychology applied to orthodontic situation for successful management of children and adult patients. The article comprises of two categories:

- Implications of physical appearance

- Treatment factors as affected by patient's state of mind.

Keywords: Motivation; Body image.
\end{abstract}

\section{Introduction}

Psychology is defined as the science dealing with human nature, function and phenomenon of soul in the main. Child psychology is defined as the science that deals with the interaction between the conscious and subconscious element in a child. Emotion is defined as an effective state of consciousness in which joy, sorrow, fear, hate or the likes are expressed. Behaviour is any change observed in the functioning of the organism. Whiplash injuries are better to treat as they are externally apparent than the psychological damage to a person as his feeling unattended and extreme emotional discomfort cannot be seen unless one has the appropriate knowledge of detecting such situations. Orthodontic treatment plays an immense role in improving the mind-set of such patients who are under confident about their external appearance. If psychology of the patient behind treatment is understood and controlled, proper cooperation of the patient is achieved, this is important to control outcome of the treatment. Orthodontic treatment provides a person a power to change themselves with a strong dense of feeling along with awareness.

Basic knowledge of psychology is necessary for modern orthodontics as most bulk of the patients comprises of those in their teenage who have a profound effect of peer and external environment on their own wellbeing. Here the "Dialectic Psychology" comes into play. Dialectic psychology is defined as the study of actions and reactions of individuals in social situations and the influence of such reactions of such individual ${ }^{1}$. Wright (1975) has defined "Behaviour Management" as a means by which dental health team effectively and efficiently performs treatment for a child and simultaneously instil a positive dental attitude in the child.

Facial identity is an important factor how a person is recognized in the society. Thus, facial aesthetics is a significant determinant of self and social attributions and perceptions ${ }^{2,3}$. Perceptions of facial aesthetics have a profound influence on psychological development from early childhood to adulthood. Knowledge of child psychology for an orthodontist is important for the following reasons:

- To understand the child better.

- To know the psychological problem of the child.

- To deliver dental; services in a meaningful and effective manner.

- To establish effective communication between the child and the parent,

- To gain confidenceof the child and parent.

- To teach the child and parent importance of [preventive orthodontics.

- To produce a comfortable environment for the orthodontic team to work on the patient. 


\section{Theories of Child psychology:}

Various psychologists have put forward following theories of child psychology which are mainly divided as Psychodynamic theories and Behavioural learning theories:

- Psychodynamic theories:

1. Psychoanalytical theory

2. Psychosocial theory

3. Cognitive theory

- Behavioural learning theories:

1. Hierarchy of needs

2. Social learning theory

3. Classical conditioning

4. Operant conditioning

These theories collectively indicate that physical attractiveness plays a major role in social interaction ${ }^{4}$ As mentioned by Freud, the Super Ego that is prevalent in the teenagers acts as a censor of acceptability of thoughts, feelings and behaviour. In such a case, the patient may deny the feeling of anxiety associated with orthodontic treatment.

Psychosocial stress may be imposed on people with dentofacial disharmonies either directly or indirectly. Direct influence can be in the form of teasing or mocking, indirect influence can be due to stereotypes. A good outcome if treatment between 12- 18 years of patients depends largely upon how well the individual has dealt with earlier developmental stages. According to studies done by Philip, orthodontic patients with deformities often fall in situations such as playground harassment among children. They are often associated with lower social attention ${ }^{5}$. Ericson in his Psychosocial theory has very described the conflict between industry versus inferiority in the age group of 7-11 years. This is profoundly affected by either of the responses; the first is the effect of response of society to the disability. The second problem of inferiority arises from the child's own reaction to the deformity ${ }^{6}$. The sense of inferiority complex is painful with a feling of incompetence, depression of varying degrees and inadequacies. Orthodontist should be vigilant in recognizing this phenomenon as it is the first manifestation of psychological effect of dentofacial deformity.

\section{Dental Consideration:}

If it is necessary to provide orthodontic treatment at an early age, it is usually preferable to do so with the parent present. At later stages, a child who never develops a sense of basic trust will be extremely frightened and uncooperative patient who needs a special effort to establish rapport and trust with the dentist. Orthodontic treatment in this age group involved wearing of removable appliances. Whether a child will do so is mainly determined whether he or she understands what is needed to please a dentist and parents, whether the peer group is supportive and whether the desired behaviour is reinforced by the dentist. Children at this stage are motivated by improved acceptance from peer group.

\section{Psychological impression of dentofacial deformity:}

Facial attractiveness is often judged by the appearance of mouth and smile. Two very popular surveys were undertaken in USA which showed consistent finding that dental appearance is very important in social interaction. It played a significant role in young people's selection of dating partners ${ }^{7,8}$.

Helm and colleagues ${ }^{9}$ in their study showed that most unfavourable self-perception of teeth was associated with overjet, crowding and extreme deep bite. Adolescence is period of intense physical development in which a unique personal identity is acquired. Shaw ${ }^{10}$ has found that children having an overjet of $7 \mathrm{~mm}$ or more, deep bite and anterior crowding reported of being teased by peers. Such children show complex behaviour especially in their teen age where physical ability is changing and academic responsibility is increasing. Failure to overcome this conflict leads to confusion.

\section{Psychological analysis for orthodontic treatment:}

Malocclusion often has psychological and sociological impact rather than somatic effects. Behavioural management of adolescence can be extremely challenging since parental authority is rejected, a poor psychological situation is created by orthodontic treatment if it is carried out primarily because the parents want it, not the child. The relationship between psychology and orthodontics has been dealt with in mechanical way. Orthodontic treatment should be instituted only if the patient wants it, not just to please parents. This is an area in which given work of irresponsible conduct occurs.

Secord and Backman ${ }^{11}$ have found small relationship between malocclusion and aesthetic appearance. Numerous other syudies have showed that psychological outcomes of orthodontics on the patient's self-image 
are positive. A moderate relationship was expressed by Lewit and Virolainen ${ }^{12}$ who correlated self-perceived orthodontic condition with objective orthodontic condition. The areas of behavioural research and application of practical psychology to the clinical practice of orthodontics can be divided into two broad categories namely social psychology and motivational psychology. It was established by Tait and Asher ${ }^{13}$ that psychosomatic patients show more attention to organ affected by illness than other organs if given a task to draw a figure.

Patients seek orthodontic treatment to improve their facial appearance. In a study that ranked malocclusions from most attractive to least attractive were Class I open bite, Class II and Class III. Yet, patients with Class II malocclusions are more motivated to undertake treatment than those with Class III malocclusion

${ }^{14}$.Baldwin and Barnes ${ }^{15}$ noted that half of a large group of candidates for orthodontic treatment were never teased for their malocclusion. Their study showed only $10 \%$ cases reported being teased. They affirmed that teasing is not necessarily an important reason for orthodontic treatment.

Dentofacial deformity has a direct effect on structure and attitude towards oneself, appearance and behaviour. Malocclusion may result in negative self-devaluation.Enhancement is one of the prime human motives. There is a knit relationship between psychological stress and anxiety especially in facially deformed individuals.

These days'lay persons are very well aware of effect of malocclusion. Counselling in orthodontic treatment involves assessment of psychologic and aesthetic implications of malocclusion. Appearance is the dominant factor for lay persons.

\section{Psychological outcomes of orthodontic treatment:}

Dentofacial aesthetic plays an important role in a child's self-concept. According to studies done by Dann et al children with serious malocclusions did not necessarily have poor self-concept and they also noted that the patient's self-concept did not improve significantly with orthodontic treatment. But contrary to Dann et al, Albino showed the psychological and social effects of orthodontic treatment ${ }^{16}$. He investigated the hypothesis that dentofacial disharmonies may have important social and significant psychological effect on patient and found that parent, peer and self-reported evaluations of dentofacial specific self-image improved significantly after patient received orthodontic treatment. Children who received orthodontic treatment felt better about their facial appearance after braces than they did before them. According to studies done by Varela psychological outcomes of orthodontic treatment differ for adults and adolescent patients with the aid of standardized psychological tests ${ }^{16}$. These researchers found a significantly positive effect of orthodontic treatment on adult patient's self-concept and after treatment these adult patients felt better about themselves, regardless of their state of mind at the outset of treatment.

Tung has given a list of social factors affecting self-concept ${ }^{17}$. These are listed below:

- Young child: Parents and teachers.

- Preadolescent: Peers, perceived attractions and perceived competence.

- Adolescents: Peers.

- Adults: Achievements and social roles.

According to Tung, preadolescent children are at a stage of developing a sense of self confidence and competence. They are aware of their own physical appearance and that of their peers. They can accurately describe their own facial features. Strength of this stage of development is that these children are more focused on the future, less concerned on the peer approval than are adolescents. They generally are still seeking the approval of significant adult role models who can be patents or health care providers. Their research also suggests that there may be racial differences on the psychological influences of orthodontics. They state "although white and minority children are similar in their self-rating and expectations for orthodontics, the former were more critical in their aesthetic judgements." They rated faces with crowded teeth, overbite and diastema more negatively than did ethnic minorities.

\section{Patient motivation for orthodontic treatment:}

Primary motive of orthodontic patients is to achieve aesthetics. Self-image is related to the problems associated with body image and self-concepts. Self-concept is related to one's ability to effectively deal with the surrounding. Body image is related to the representation of the physical self in which unconscious attitude about the body, its functioning, structure and appearance are incorporated.Thus, self-image and identity can be used for motivating adolescent patients.Burstone reported a poor relationship between uncooperative patients and their parents ${ }^{18}$. 


\section{Orthodontic treatment timings:}

There is an on-going debate pertaining to ideal time for orthodontic treatment. Case selection based upon severity and type of malocclusion is an important factor. Thus age and type of malocclusion are important considerations before one begins the orthodontic treatment.Burns ${ }^{21}$ has mentioned the inadequacy of instructions in handling patients. He notes that "no general set of suggestions is applicable for handling patients as a group, since they show wide variation in physical development, emotional maturity, social experiences, attitude towards authority and ability to accept responsibility".

\section{Motivational psychology:}

Patient compliance is the prime "mantra" of successful orthodontic treatment. Headgear effects, functional appliances treatment, oral hygiene and keeping appointments are all dependent upon patient complying with the doctor's instructions. Egolf described a compliant patient as one who practices good oral hygiene, wears appliances as instructed without abusing them, follows an appropriate diet and keeps appointments ${ }^{22}$. Adults are generally compliant patients but adolescents are generally in the orthodontist's office because a part has brought them there and their goals for treatment are frequently non-specific. Southard et al pointed out that the assurance of good compliance can be difficult in case of adolescent ${ }^{23}$. Compliance by the patient helps achieve treatment objectives in a minimum treatment time and improved co-operation of the patient can also reduce expences of orthodontic treatment.According to Nanda, Sinha, the efficiency of care and improved oral hygiene can decrease damage to periodontal tissues and limit effects of enamel decalcification and caries $^{24}$.

\section{Conclusions}

Gaining patient's trust is immensely important. Most of the times, the patient depends upon the orthodontist's decision about the treatment process. It is not mandatory that all patients will finish treatment successfully. Some may fail to comply. It does not mean that the fault lies to the orthodontist. Unexpected growth manifestation can hamper a successful treatment outcome. A vigilant orthodontist is successful in addressing malocclusion as well as psychological frustrations of the patient. Thus case history should involve not only the details of the patient but also the note of his family and environment.

\section{References}

[1]. Giddon B. D.: Psychologic problems of physically handicapped. IDJ 1975; 25: 576-581.

[2]. Gershater M. M.: A study of orthodontic problems of 465 emotionally disturbed children. Thesis, 1954

[3]. Brandhorst O. W.: Will orthodontics become a part of contemplated government health program for children? J. D. Educ. 1946; 10; 138-143.

[4]. Heidi K., Hannu H., Tallervo L. and William C. S: The influence of incisal malocclusion on the social attractiveness of young adults in Finland. Eur. J. Orthod. 1995; 17: 505-512.

[5]. Ceib Phillips, Elizabeth Bennett and Hillary L. Broder: Angle Orthod. 1998; 68 (6): 547-555

[6]. George S.: Psychological issues pertaining to malocclusion. Am. J. Orthod. 1970; 58 (3): 276-283.

[7]. Varela M., Garcia C.: Impact of orthodontics on the psychologic profile of adult patients: a prospective study. Am. J. Orthod. 1997; 95: 142-148.

[8]. Brown and Moerenhout: Pain experience and psychological adjustment to treatment. Am. J. Orthod. 1997; 91: $349-356$

[9]. Helm S., Kereiborg S., Solow B.: Psychological implication of malocclusion: A 15 year follows up study on 30 years. Old Danes. Am. J. Orthod. 1997; 85: 110-118.

[10]. Shaw W: The influence of children's dentofacial appearance on their social attractiveness as judged by peers and lay adults. Am. J. Orthod. 1981; 79: 399-415.

[11]. Secord P. F., Backman C. W.: Malocclusion and psychological factors. J. Amer. Dent. Acs. 1959; 59 : $931-938$.

[12]. Lewit D. W. and Virolainen K.: Conformity and independence in adolescents' motivation for orthodontic treatment. Child Develop 1968; 39: 1189-1200.

[13]. Tait C. D., Asher R.: Inside of the body test: a preliminary report. Psychosom. Med. 1955; $17: 139$.

[14]. Wilmont J. J., Barber H. D., Chou D. G., Vig K. W.: Associations between severity of dentofacial deformity and motivation for orthodontic orthognathic surgery treatment. Angle Orthod. 1993; 63: 283-288.

[15]. Baldwin D. C., Barnes M. L.: Psychological factors motivating orthodontic treatment. I. A. D. R. $1965 ; 44: 461$.

[16]. Albino J. E.: Psychological reasons for orthodontic treatment explored. J. Am. Dent. Assoc. 1998; $1002-1003$.

[17]. Alice W., Tung B. S. AsumanKiyak: Psychological influences on the timing of orthodontic treatment. Am. J. Orthod. 1998; 113 (1): 29-39.

[18]. Kreit L. H., Burstone C., Delmon L.: Patient cooperation in orthodontic treatment. J. Amer. Coll. Dent. 1968; 35: 327-332.

[19]. Alex Jacobson: Psychology and early orthodontic treatment. Am J. Orthod. 1979; 76 (5): 511-529.

[20]. Adrian Becker, Joseph Shapira and Stella Chaushu: Orthodontic treatment for disabled children: Motivation, expectation and satisfaction. Eur. J. Orthod. 2000; 22: 151-158.

[21]. Michael H. Burns: Chapter 15. Psychological aspects of orthodontics. Applied psychology. Page 200-207.

[22]. Elgof R. J.: Factors associated with orthodontic patient compliance with intraoral elastic and headgear wear. Am. J. Orthod. Dentofacial Ortho. 1997; 97: 336-348.

[23]. Southard K. A.: Application of the millon adolescent personality inventory in evaluating orthodontic compliance. Am. J. Orthod. DentofacialOrthop. 1991; 100: 553-561.

[24]. Sinha P. K., Nanda R. S., McNeil D. W.: Percieved orthodontist behaviour that predict patient satisfaction, orthodontist-patient relationship and patient adherence in orthodontic treatment. Am. J. Orthod. DentofacialOrthop. 1996; 110 (4): $370-377$. 